\title{
Busca retrospectiva da transmissão maternal da infecção chagásica em pacientes na fase crônica
}

\author{
A retrospective search for maternal transmission of Chagas \\ infection from patients in the chronic phase
}

\author{
Anis Rassi ${ }^{1}$, Vicente Amato Neto ${ }^{2}$, Gustavo Gabriel Rassi ${ }^{1}$, Valdir Sabbaga Amato ${ }^{2}$, \\ Anis Rassi Júnior ${ }^{1}$, Alejandro 0. Luquetti ${ }^{3}$ e Sérgio Gabriel Rassi ${ }^{1}$
}

\begin{abstract}
RESUMO
Avaliamos a transmissão maternal do Trypanosoma cruzi em 278 filhos de 145 mães com a doença crônica causada por esse protozoário, nascidos após o estabelecimento do diagnóstico materno. Usamos, nas mães e nos filhos, provas sorológicas como base do objetivo do estudo. Verificamos que ocorreram apenas duas veiculações pela modalidade citada $(2 / 278=0,7 \%)$. Como houve amamentação, não foi possível diferenciar, nesses casos, a transmissão congênita da adquirida pelo leite, mas, de qualquer forma, processou-se transmissão maternal, que constitui uma das modalidades alternativas de infecção pelo Trypanosoma cruzi. A metodologia empregada é mais uma dentre as diversas propostas para aquilatar a prevalência desse tipo de propagação do Trypanosoma cruzi. Ao lado da constatação fundamental, registramos fatos relacionados com a gestação, parto, puerpério, abortamento, prematuridade, nati-neomortalidade e aleitamento materno, que podem representar subsídios para melhores interpretações sobre 0 assunto.
\end{abstract}

Palavras-chaves: Infecção pelo Trypanosoma cruzi. Transmissão maternal. Estudo retrospectivo.

\begin{abstract}
Maternal transmission of Trypanosoma cruzi from 278 children of 145 mothers, chronically infected with this protozoan, to their offspring was investigated. This study was based upon serological tests. In only two cases $(2 / 278=0.7 \%)$, such mode of transmission was demonstrated to have occurred. However, as according to extant records both patients had also been breast-fed, and the contribution of this factor could not be ruled out. In any case, maternal transmission, an alternative mode of acquiring the infection with Trypanosoma cruzi, was demonstrated. The methodology used is a further contribution to the evaluation of the prevalence of this propagating mechanism of T. cruzi; in addition to those aimed at the main objective of the investigation, records were kept about pregnancy, parturition, puerperium, abortion, prematurity, perinatal deaths and breast-feeding, which might contribute to a better interpretation of the subject.
\end{abstract}

Key-words: Trypanosoma cruzi infection. Maternal transmission. Retrospective study.

№ Brasil e em alguns outros países latino-americanos, a transmissão do Trypanosoma cruzi a seres humanos, através de triatomíneos, ficou muito menos expressiva e, inclusive, já foram certificadas interrupções desse tipo de veiculação do parasita ${ }^{22}$. Como decorrência de tal situação as conhecidas formas de infecção rotuladas como alternativas passaram a merecer maiores atenções, porquanto os atingidos pela protozoose continuam podendo causar novos comprometimentos, capazes então de prejudicar o pleno êxito de medidas preventivas adotadas até agora.

Como recordação, lembramos que são as seguintes as modalidades alternativas de veiculação do $\mathrm{T}$. cruzi dignas de cuidados profiláticos adequados: congênita, por leite materno, por transfusão de sangue, por transplante de órgão, acidental em laboratórios e pela via oral ${ }^{11}$. Não convém qualificá-las como

\footnotetext{
1. Anis Rassi Hospital, Goiânia, GO, Brasil. 2. Laboratório de Investigação Médica - Parasitologia do Hospital das Clínicas da Faculdade de Medicina da Universidade de São Paulo, São Paulo, SP, Brasil. 3. Instituto de Patologia Tropical e Saúde Pública da Universidade Federal de Goiás, Goiânia, G0, Brasil.

Endereço para correspondência: Prof. Anis Rassi. Av. José Alves 453, Setor Oeste, 74110-020 Goiânia, G0, Brasil.

Tel: 5562 227-9000, Fax: 5562 259-9839

e-mail: arassi@arh.com.br

Recebido para publicação em 09/01/04

Aceito em 8/9/2004
} 
excepcionais, pois o número de pessoas sob risco é expressivo. Alguns outros perigos ficaram alvos de especulações, mas provavelmente não têm, no âmbito da saúde pública, significado relevante.

A transmissão maternal ou vertical da doença de Chagas já foi relatada em diversas comunicações científicas, que permitem as seguintes considerações 2345671214151618192021 . Sua frequêencia varia, de acordo com a região e a metodologia de estudo, de 1,6 a 18,5\%?. Trata-se de mecanismo de perpetuação dessa enfermidade parasitária que vem crescendo de importância nas últimas décadas em regiões endêmicas e urbanas, onde estão concentrados muitos migrantes acometidos pelo T. cruzi. Estudos das décadas de $60 \mathrm{e}$ 70 mostraram, por meio de exame anatomopatológico de fetos, natimortos e prematuros, evolução fatal intra-uterina dessa infecção. A partir da década de 80 , pesquisas prospectivas evidenciaram, através de diferentes métodos para diagnóstico, tais como parasitológico, sorológico e anatomopatológico, formas variadas da citada modalidade da doença de Chagas. Estas podem apresentarse de diversas maneiras, exemplificadas por óbito fetal em qualquer fase da gestação, prematuridade, hepatoesplenomegalia, febre, anemia, icterícia emeningoencefalite; em cerca de $50 \%$ dos casos 0 recém-nascido pode apresentar-se sem sintomas ou oligossintomático. Os fatores possibilitadores da transmissão materno-fetal do T. cruzi não estão bem esclarecidos: a cepa e a presença de parasitas circulantes podem estar envolvidas. 0 diagnóstico é muitas vezes confirmado pela presença do protozoário no recém-nascido ao exame direto ou pelo xenodiagnóstico. Os anticorpos da classe IgM anti-T. cruzi são detectáveis por imunofluorescência indireta e EUSA, cumprindo assinalar que, às vezes, são de aparecimento tardio ( decorridos vários meses após o nascimento), exigindo pesquisas múltiplas para sua detecção, ao contrário do observado em casos agudos não-congênitos ${ }^{3}$. A persistência de anticorpos específicos da classe IgG por um período maior que 6 meses indica infecção congênita. 0 tratamento precoce, com benznidazol ou nifurtimox, é apto a propiciar cura em $3 / 4 \mathrm{dos}$ casos, em média, segundo dados da literatura?.

Com 0 intuito de contribuir no contexto do tema efetuamos avaliação baseada na busca de infectados verticalmente, tendo como casuística filhos de mulheres com doença de Chagas nascidos vivos após o diagnóstico da infecção na mãe e analisados por exames sorológicos quando estavam com idades variáveis. Os resultados obtidos são presentemente comunicados.

Paralelamente, relatamos fatos relacionados com gestação, parto, puerpério, abortamento, prematuridade, natineomortalidade e aleitamento materno, que podem representar subsídios para melhores interpretações sobre 0 assunto.

\section{MATERIAL E MÉTODOS}

Em prontuário previamente planejado reunimos os dados coletados acerca das mulheres que compuseram a casuística e dos filhos que pudemos incluir na investigação.

Quanto às mães, preocupamo-nos com idade, época da confirmação do diagnóstico por testes sorológicos, resultado do eletrocardiograma, apreciação radiológica do tórax em especial para visibilização da área cardíaca e história obstétrica posteriormente ao reconhecimento da presença da doença de Chagas (gestação, parto, puerpério, abortamento, prematuridade e natineomortalidade). Apenas 4 mães haviam recebido tratamento específico na fase aguda acompanhada pelo Autor, porém, continuaram infectadas (xenodiagnóstico e provas sorológicas positivos). Quanto aos filhos, apuramos quantos investigados corresponderam a cada mãe, peso ao nascer, idade na época de nossa intervenção, ocorrência ou não de aleitamento materno com a respectiva duração do mesmo, antecedente de transfusão de sangue, eventual contato com triatomíneos e resultados de provas sorológicas.

Pudemos conhecer a situação, relativa à doença de Chagas, de todos os filhos nascidos após o diagnóstico da infecção na mãe, à exceção de 16 ( 4 vivos, não alcançáveis e 12 falecidos, sendo dois natimortos e 10 neomortos, um por descolamento prematuro de placenta, dois por tétano umbilical, um por pneumonia e 6 de causa ignorada. À exceção dos dois natimortos e de 3 neomortos de causa ignorada, de peso não conhecido, os 11 demais nasceram com peso superior a $2.500 \mathrm{~g}$ ).

A composição da casuística teve início em 1975 e prosseguiu até os dias atuais.

Globalmente, formaram a casuística 145 mulheres e 278 filhos.

0 diagnóstico de doença de Chagas nas mães dependeu da positividade de provas sorológicas. Todas foram submetidas a exame clínico, eletrocardiograma e exame radiológico do tórax.

Usamos 4 tipos de testes sorológicos: fixação do complemento ${ }^{13}$, hemaglutinação indireta ${ }^{10}$, imunoenzimático (ELISA) ${ }^{23}$ e imunofluorescência indireta ${ }^{9}$. Para diagnóstico contamos sempre com pelo menos dois, quanto às mães e filhos, se bem que muitas vezes recorremos a 3 .

Exames anatomopatológicos de natimortos, neomortos ou de produtos de abortamentos não fizeram parte do estudo, dada sua natureza retrospectiva; esses acontecimentos foram registrados em interrogatório sobre a história obstétrica da mãe.

\section{RESULTAD0S}

No conjunto de 278 filhos de 145 mães, apenas dois adquiriram a infecção maternal, a seguir descritos:

1 o caso (MAPS). Trata-se de um menino de 5 anos de idade, no qual as provas sorológicas foram positivas (imunofluorescência indireta: 1/160, hemaglutinação indireta: 1/52 e ELISA: 4,5), nascido por intermédio de cesárea e pesando 2.350g. Foi amamentado pela mãe durante 4 meses, não recebeu transfusão de sangue e não houve possibilidade de transmissão por triatomíneo. Nasceu em zona urbana de Goiânia (GO), de onde nunca saiu. Constituiu o primeiro de dois filhos de mulher de cor parda, com 32 anos, natural do Estado de Tocantins, apresentando a forma cardíaca, classe funcional II da NYHA e que contava história de contato com triatomíneos até 14 anos de idade, quando migrou para zona urbana de Goiânia (G0) . Os mesmos testes sorológicos concernentes ao irmão mais jovem 
( fruto da $2^{\mathrm{a}} \mathrm{e}$ última gestação) foram negativos. No menino referido 0 xenodiagnóstico resultou positivo e 0 eletrocardiograma e 0 ecocardiograma resultaram normais. Foi tratado com benznidazol ( $5 \mathrm{mg} / \mathrm{kg}$ de peso corporal/60 dias), sem efeito colateral, achandose em fase de avaliação da ação terapêutica.

2 caso (FMM). Foi observado enquanto os revisores analisavam este trabalho. Refere-se a paciente com 15 anos de idade, no $4^{0}$ mês da primeira gestação. Em virtude da mãe apresentar cardiopatia chagásica crônica que posteriormente motivou 0 implante de marcapasso cardíaco artificial, foi submetida a provas sorológicas para doença de Chagas aos 3 meses de idade, com resultado positivo, o que atesta, no mínimo, transmissão passiva de anticorpos pela circulação placentária. Entretanto, aos 2 e aos 4 anos de idade as referidas provas continuaram positivas. Nasceu de parto normal, pesando $3.000 \mathrm{~g}$, em zona urbana de Goiânia (G0), de onde nunca saiu, sem contato com triatomíneos e sem antecedente de transfusão de sangue. Amamentou ao seio materno durante 6 meses. Aos 14 anos foi tratada com benznidazol ( $200 \mathrm{mg} / \mathrm{dia} / 50$ dias) , prescito por outro colega, sem efeito colateral. Suas reações tiveram os seguintes resultados: imunofluorescência indireta, 1/160, hemaglutinação indireta, 1/16 e ELISA, 3,4; 0 xenodiagnóstico resultou negativo ( 3 exames) e 0 eletrocardiograma e 0 ecocardiograma foram normais. A mãe, de cor branca, com 20 anos por ocasião de seu nascimento, natural do Estado de Goiás, com história de contato com triatomíneos até 12 anos de idade, teve mais uma filha ( $2^{-}$gestação), em quem as 3 provas sorológicas para doença de Chagas resultaram negativas.

Eletrocardiograma e exame radiológico do tórax mostraramse normais em 88 (60,7\%) mães, em classe funcional I da NYHA e presença de cardiopatia em 57 ou 39,3\% (classe funcional I em 44, II em 8 e III em 5).

Com relação às gestações só uma ocorrência é registrável: exérese do colo do útero, no primeiro mês, em virtude de câncer; por cesárea, nasceu criança prematura e o puerpério foi normal.

Quanto aos partos, $146(50,5 \%)$ foram normais, 140 (48,5\%) foram cesáreos e $3(1,0 \%)$ a fórceps; ocorreram 3 partos com dois gêmeos e um parto trigemelar.

Em relação aos puerpérios, apenas registramos, em uma eventualidade, insuficiência cardíaca global nessa fase, sem outras particularidades citáveis e nascimento de gêmeos em operação cesárea.

Abortamento espontâneo. Ocorreram 30 abortos em 21 mulheres ( 26 no $1^{1}$ trimestre de gestação e 4 no $2^{\circ}$ ), sendo 5 na

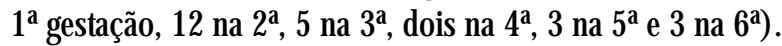

Eventual participação de triatomíneos. Dentre todos os filhos, 35 estiveram, ocasionalmente, em lugares onde existiam os insetos; porém, moravam habitualmente em áreas e residências nas quais não havia a presença deles.

Transfusão de sangue. Recebida por 11 filhos; em 9 houve uma única e em dois foram efetuadas 3 em cada um deles.

Outros dados, referentes às mães e aos filhos, encontramse nas Tabelas 1 e 2.

Tabela 1 - Cor, idade, naturalidade e número de filhos das mães em que se estudou a transmissão materna da doença de Chagas.

\begin{tabular}{|c|c|c|c|}
\hline Dados & & Número & Porcentagem \\
\hline \multicolumn{4}{|l|}{ Cor } \\
\hline branca & & 135 & 93,1 \\
\hline parda & & 8 & 5,5 \\
\hline preta & & 2 & 1,4 \\
\hline \multicolumn{4}{|l|}{ Idade (anos)* } \\
\hline 15 a 19 & & 12 & 8,3 \\
\hline 20 a 29 & & 81 & 55,9 \\
\hline 30 a 39 & & 48 & 33,1 \\
\hline 40 a 49 & & 4 & 2,7 \\
\hline \multicolumn{4}{|l|}{ Epidemiologia** } \\
\hline Goiás & & 103 & 71,5 \\
\hline Minas Gerais & & 29 & 20,1 \\
\hline Bahia & & 6 & 4,2 \\
\hline Tocantins & & 3 & 2,1 \\
\hline São Paulo & & 2 & 1,4 \\
\hline Piauí & & 1 & 0,7 \\
\hline \multicolumn{4}{|c|}{ Filhos examinados por mãe } \\
\hline no de filhos & & no de mães & \\
\hline 1 & $\mathrm{x}$ & 62 & 42,7 \\
\hline 2 & $\mathrm{x}$ & 50 & 34,5 \\
\hline 3 & $\mathrm{x}$ & 26 & 17,9 \\
\hline 4 & $\mathrm{x}$ & 2 & 1,4 \\
\hline 5 & $\mathrm{x}$ & 2 & 1,4 \\
\hline 6 & $\mathrm{x}$ & 1 & 0,7 \\
\hline 7 & $\mathrm{x}$ & 2 & 1,4 \\
\hline
\end{tabular}

* Por ocasião do nascimento do primeiro filho examinado. ** Refere-se ao Estado do Brasil em que nasceu e no qual muito provavelmente adquiriu a infecção; não computado um caso, no qual a transmissão se deu por exsangǘneotransfusão.

Tabela 2 - Sexo, peso ao nascer, amamentação e sorologia realizada em filhos de mães chagásicas.

\begin{tabular}{|c|c|c|}
\hline Dados & Número & Porcentagem \\
\hline \multicolumn{3}{|l|}{ Sexo } \\
\hline masculino & 140 & 50,3 \\
\hline feminino & 138 & 49,7 \\
\hline \multicolumn{3}{|l|}{ Peso ao nascer } \\
\hline$<2.500 \mathrm{~g}$ & 21 & 7,6 \\
\hline$\geq 2.500 \mathrm{~g}$ & 257 & 92,4 \\
\hline \multicolumn{3}{|c|}{ Amamentação ao seio materno } \\
\hline 0 dia & 25 & 9,0 \\
\hline 7 a 29 dias & 23 & 8,3 \\
\hline 1 a 5 meses & 117 & 42,1 \\
\hline 6 a 12 meses & 65 & 23,4 \\
\hline 1 ano & 27 & 9,7 \\
\hline 2 a 3 anos & 17 & 6,1 \\
\hline 4 a 5 anos & 4 & 1,4 \\
\hline \multicolumn{3}{|c|}{ Idade em que foram submetidos às PS* } \\
\hline 3 meses & 1 & 0,4 \\
\hline 5 a 6 meses & 10 & 3,6 \\
\hline 7 a 11 meses & 16 & 5,7 \\
\hline 1 a 10 anos & 155 & 55,8 \\
\hline 11 a 20 anos & 61 & 22,0 \\
\hline 21 a 30 anos & 26 & 9,3 \\
\hline 31 a 40 anos & 9 & 3,2 \\
\hline \multicolumn{3}{|l|}{ PS* utilizadas } \\
\hline $\mathrm{RFC}+\mathrm{IFI}$ & 148 & 53,2 \\
\hline $\mathrm{IFI}+\mathrm{HAI}+\mathrm{ELISA}$ & 102 & 36,7 \\
\hline $\mathrm{RFC}+\mathrm{IFI}+\mathrm{HAI}$ & 18 & 6,5 \\
\hline $\mathrm{HAI}+\mathrm{IFI}$ & 6 & 2,2 \\
\hline $\mathrm{RFC}+\mathrm{HAI}$ & 2 & 0,7 \\
\hline HAI + ELSA & 2 & 0,7 \\
\hline
\end{tabular}




\section{DISCUSSÃ0}

Procuramos contribuir para melhor conhecimento possível da realidade ligada à transmissão maternal da infecção devida ao T. cruzi. Usamos tipo não usual de averiguação, adicionável a outras maneiras já propostas com a finalidade de demarcar a intensidade segundo a qual manifesta-se 0 problema. Registramos apenas duas positividades dentre 278 filhos de 145 mães com doença de Chagas crônica, nascidos depois do diagnóstico da parasitose nessas mulheres. É cifra que pode representar um parâmetro, comparável com outros estabelecidos em estudos congêneres e útil em avaliações futuras de eventuais efeitos de medidas preventivas. Ao mesmo tempo, procuramos cooperar com informações paralelas, de caráter obstétrico, a fim de possibilitar bom entendimento da questão.

Nosso objetivo básico foi procurar evidenciar a transmissão materna da infecção pelo T. cruzi em filhos, com idades variadas, de mulheres acometidas de doença de Chagas crônica. № entanto, alguns fatos paralelamente notados, sobretudo compondo as documentações obstétricas, devem ser destacados porque retratam circunstâncias ilustrativas e que, acreditamos, valer a pena conhecer. Assim, é destacável a verificação de 140 (48,5\%) partos cesáreos, no conjunto dos constituintes da casuística. É cifra sem dúvida elevada, decorrente comumente de influências não médico-assistenciais e, acima de tudo, da comodidade de obstetras. № Estado de Goiás, por exemplo, em 2001 ocorreram 59.116 partos a cargo do Sistema Único de Saúde ( SUS) , dos quais 46.072 (77,9\%) foram normais e 13.044 $(22,1 \%)$ cesáreos $^{17}$. Também, vale citar que em 253 dentre 278 (91\%) conceptos houve amamentação pela mãe, demarcando acontecimento infelizmente infreqüente em razoável porção de regiões do país.

Quantificando a comprovação de duas transmissões por mecanismo alternativo, muito provavelmente congênito e porventura por aleitamento, ficam estabelecidas as seguintes cifras: dois (0,7\%) em 278 filhos; dois (1,4\%) em 145 mães e dois $(0,7 \%)$ em 289 partos.

Como computamos outros números, certamente prestimosos para boa avaliação global do tema gravidez - doença de Chagas, interpretamos como conveniente registrá-los: em 319 gestações, $30(9,4 \%)$ abortamentos, 26 (8,1\%) recém-nascidos (21 vivos e 5 mortos) com peso inferior a $2.500 \mathrm{~g}$, dois $(0,6 \%)$ natimortos e $6(1,9 \%)$ neomortos de causa ignorada. Obviamente, não examinamos os produtos de abortamento e nem os natimortos e neomortos por tratar-se de estudo retrospectivo.
Como não tivemos grupo controle (mães não-chagásicas) para comparar nossos resultados no tocante à prevalência de aborto espontâneo, prematuridade e mortalidade perinatal, cotejamo-los com os de Bittencourt ${ }^{3}$, cujo material, por seu perfil sócio-econômico, é semelhante ao nosso. Elaboramos então a Tabela 3, pela qual se vê que 0 aborto espontâneo ea natimortalidade foram significativamente menores em nosso material e que a prematuridade ea neomortalidade não evidenciaram diferenças estatisticamente significativas. Assim, a rigor, não se pode filiar tais eventos, em nossa casuística, à doença de Chagas, pelo menos em sentido absoluto. Aliás, a autora, que detém a maior experiência no Brasil a respeito do tema, concluiu que nas mães chagásicas que não transmitiram sua infecção ao feto não houve maior freqüência de aborto, prematuridade e mortalidade perinatal, confirmando observações de outros autores no Brasil; ressaltou, entretanto, que nas mães que transmitiram a infecção houve uma maior tendência à natimortalidade.

Interpretamos como elogiável e significativa a maneira como as mães prestaram informações, respondendo com precisão e prontidão. Dados concernentes à história obstétrica, ao peso do concepto e dia de seu nascimento, bem como o tempo de amamentação, foram quase sempre fornecidos a contento. Essas prestimosas colaborações independeram de níveis sociais e traduzem, indubitavelmente, a divina benção da maternidade.

0 resultado do estudo, como desfecho da tramitação estipulada, situou-se na verificação de que dois filhos adquiriram a infecção verticalmente. A segura confirmação da existência da parasitose deu-se de acordo com a metodologia adotada e outros fatores influentes não participaram, com exceção da ocorrência de amamentação ao seio materno em ambos os casos. Este meio de veiculação do parasita tem sido documentado com muito pouca freqüência ${ }^{8}$. No entanto, respeito a necessário rigor não permite excluir a vigência dessa modalidade alternativa de transmissão, mas de qualquer forma aconteceu passagem do T. cruzi da mãe ao filho, demarcando validade dessa circunstância por meio do critério que usamos, ou seja, procura em filhos nascidos vivos de mulheres com doença de Chagas crônica.

Percebemos que a presença de cardiopatia, desde que assistida e sem maior gravidade, não contra-indica a gestação e nem 0 parto.

Transfusões de sangue, eventuais permanências em lugares onde poderiam estar presentes triatomíneos e prematuridade não propiciaram infecções segundo a metodologia e 0 tipo de avaliação que empregamos.

A conduta que adotamos não é usual e constitui forma diferente de medir a transmissão maternal, podendo auxiliar

Tabela 3- Comparação da ocorrência de aborto espontâneo, prematuridade, natimortalidadee neomortalidade entre mães não-chagásicas e mães chagásicas.

\begin{tabular}{lcccccc}
\hline Autor & Material & $\begin{array}{c}\text { № de } \\
\text { gestações }\end{array}$ & $\begin{array}{c}\text { Aborto } \\
\text { espontâneo }\end{array}$ & Prematuridade & Natimortalidade & Neomortalidade \\
\hline Bittencourt3 & Mães não-chagásicas & 522 & $17,0 \%$ & $7,6 \%$ & $3,4 \%$ & $4,7 \%$ \\
Os autores & Mães chagásicas & 319 & $9,4 \%$ & $8,1 \%$ & $0,6 \%$ & $1,9 \%$ \\
& & $p$ & $0,003(\mathrm{~S})$ & 0,430 (NS) & 0,018 ( S) & 0,056 (NS) \\
\hline
\end{tabular}

S: diferença estatisticamente significativa; NS: não significativa. 
na obtenção de informes epidemiológicos e em tarefas assistenciais, como o tratamento específico precoce das crianças, cuja demonstração de cura (negativação das provas sorológicas) se faz em poucos anos e em $76 \%$ dos casos?

As porcentagens de casos decorrentes de infecções congênitas são estipuladas mediante uso de metodologias bastante diversas. Além disso, porém, fatores influentes são habitualmente citados e entre eles as cepas do T. cruzi e variações regionais. Neste estudo, as mães adquiriram a parasitose em localidades de 6 estados, principalmente Goiás (71\%); não realizamos determinações relacionadas com cepas.

A taxa de positividade $(0,7 \%)$ que verificamos é pequena se considerarmos o número de filhos avaliados (2/278). Se fosse possível ver repetidas globalmente as características do grupo que analisamos, apenas especulativamente, pelo menos no Brasil, em 1.000 filhos seriam reveladas de forma grosseira cerca de 7 a 8 infecções congêneres às que registramos.

É atualmente necessário coibir a participação de modalidades alternativas de transmissão do T. cruzi. Em publicação recente ${ }^{11}$ foram sistematizadas as possibilidades preventivas, inclusive quanto às formas congênita ou dependente de aleitamento natural. As medidas adotadas nem sempre são viáveis em termos de efetividade e simplicidade. Entretanto, até agora determinadas atitudes ficaram consensualmente aceitas: não se pode impedir gravidez, é adequado aconselhamento relacionado com nova gestação se já houve alguma confirmação de transmissão e contra-indicação formal para nova prenhez afigura-se inconveniente, se bem que parece existir maior risco de transmissão quando ela ocorre em ocasiões sucessivas. Também não se deve proibir aleitamento natural, exceto quando a mãe estiver na fase aguda da infecção ou apresentar sangramento mamilar.

\section{REFERÊNCIAS BIBLIOGRÁFICAS}

1. Amato Neto V, Martins JEC, Oliveira L, Tsuzuki E. Incidência da doença de Chagas entre gestantes, no Hospital das Clínicas de São Paulo. Revista do Instituto de Medicina Tropical de São Paulo 7: 156-159, 1965.

2. Amato Neto V, Martins JEC, Oliveira L, Tsuzuki E. Incidência da doença de Chagas entre mães de prematuros, no Hospital das Clínicas de São Paulo. Revista do Instituto de Medicina Tropical de São Paulo 10: 192-195, 1968.

3. Bittencourt AL. Doença de Chagas congênita na Bahia. Revista Baiana de Saúde Pública 11: 165-208, 1984.

4. Bittencourt AL. Actual aspects and epidemiological significance of congenital transmission of Chagas' disease. Memórias do Instituto Oswaldo Cruz 79 ( supl): 133-137, 1984.

5. Bittencourt AL. Possible risk factors for vertical transmission of Chagas' disease. Revista do Instituto de Medicina Tropical de São Paulo 34: 403408, 1992.
6. Bittencourt AL. Infecções congênitas transplacentárias. Revinter, Rio de Janeiro, 1995

7. Bittencourt AL. Transmissão vertical da doença de Chagas. Revista de Patologia Tropical 29 ( supl): 101-113, 2000.

8. Bittencourt AL, Sadigursky M, Silva AA, Menezes CAS, Marianetti MMM, Guerra SC, Sherlock I. Evaluation of Chagas'disease transmission throught breast-feeding. Memórias do Instituto Oswaldo Cruz 83: 37-39, 1988.

9. Camargo ME. Fluorescent antibody test for the serodiagnosis of American trypanosomiasis. Technical modification employing preserved culture forms of Trypanosoma cruzi in a slide test. Revista do Instituto de Medicina Tropical de São Paulo 8:227-234, 1966.

10. Cerisola JA, Chaben MF, Lazzari J0. Test de hemaglutinación para el diagnóstico de la enfermedad de Chagas. Prensa Médica Argentina 49: 1761-1767, 1962

11. Chieffi PP, Amato Neto V. Prevenção referente às modalidades alternativas de transmissão do Trypanosoma cruzi. CLB Balieiro Editores, São Paulo, 2000.

12. Freilij H, Altcheh J. Congenital Chagas' disease: diagnostic and clinical aspects. Clinical Infectious Diseases 21: 551-555, 1995.

13. Freitas JLP, Almeida J0. Nova técnica de fixação do complemento para moléstia de Chagas (Reação quantitativa com antígeno gelificado de culturas de Trypanosoma cruzi). Hospital ( Rio de Janeiro) 35: 787-800, 1949.

14. Howard J, Rubio M. Congenital Chagas' disease. I. Clinical and epidemiological study of thirty cases. Boletín Chileno de Parasitología 23: 107-112, 1968.

15. Medina-Lopes MD. Transmissão do Trypanosoma cruzi em um caso, durante aleitamento, em área não endêmica. Revista da Sociedade Brasileira de Medicina Tropical 21: 151-153, 1988.

16. Medina-Lopes MD. Transmissão materno-infantil da doença de Chagas. Tese de Mestrado, Faculdade de Medicina da Universidade de Brasília, Brasília, DF, 1983.

17. Ministério da Saúde. Sistema de Informações Hospitalares do SUS ( SIH/ SUS) . http://tabnet.datasus.gov.br/cgi/tabcgi.exe?sih/cnv/prgo.def. Acessado em 06/07/2004.

18. Mota CCC. Doença de Chagas congênita: estudo longitudinal das repercussões da infecção materna no concepto, do nascimento aos cinco anos de idade. Tese de Doutorado, Faculdade de Medicina da Universidade Federal de Minas Gerais, Belo Horizonte, MG, 1992.

19. Nisida IVV, Amato Neto V, Braz LMA, Duarte MIS, Umezawa ES. A survey of congenital Chagas' disease, carried out at three health institutions in São Paulo city, Brazil. Revista do Instituto de Medicina Tropical de São Paulo 41:305-311, 1999.

20. Pehrson PO, Wahlgren M, Bengtsson E. Asymptomatic congenital Chagas' disease in a 5-year-old child. Scandinavian Journal of Infectious Diseases 13:307-308, 1981.

21. Schenone H, Contreras M, Del C, Borgoño JM, Rojas A, Tello P, Salinas P. Algunas características clínicas y parasitológicas de la enfermedad de Chagas congénita en Chile. Pediatría 32: 65-72, 1989.

22. Silveira AC, Arias AR, Segura E, Guillén G, Russomando G, Schenone H, Dias JCP, Padilla JV, Lorca M, Salvatella R. El control de la enfermedad de Chagas en los paises del cono sur de América. História de una iniciativa internacional. 1991/2001. Faculdade de Medicina do Triângulo Mineiro. Uberaba, MG, 2002.

23. Voller A, Draper C, Bidwell DE, Bartlett A. Microplate enzyme-linked immunosorbent assay for Chagas' disease. Lanceti ( 7904) : 426-428, 1975. 